\title{
Reflexões sobre a subjetividade na gestão a partir do paradigma da organização que aprende
}

\author{
Reflections about subjectivity in administration \\ from learning organization model
}

\begin{abstract}
Correlations were established between subjectivity and organizational administration from Peter Senge's learning organization model. Their principal analytical issues comes from organization learning concept that articulates individual and social learning by communication and from the leadership concept considered as a social capacity to model the future dependent on attitudes and skills of individual or subjective nature.

Key words Administration and learning organization, Subjectivity and administration, Organizational leadership
\end{abstract}

Resumo $O$ artigo estabelece correlações entre subjetividade e gestão organizacional a partir do paradigma da organização que aprende, de Peter Senge. Os principais eixos analíticos do mesmo são o conceito de aprendizagem organizacional, como processo que articula a aprendizagem individual e social, através da comunicação, e o conceito de liderança, visto como capacidade social de moldar o futuro que depende da disseminação de qualidades e atitudes que dependem de características de nature$z a$ individual ou subjetiva.

Palavras-chave Gestão e aprendizagem organizacional, Subjetividade e gestão, Liderança organizacional

\footnotetext{
1 Departamento de

Administração e

Planejamento, Escola

Nacional de Saúde Pública

Fundação Oswaldo Cruz.

Rua Leopoldo Bulhões,

$1.480 / 7$ o andar -

Manguinhos - 21041-210 -

Rio de Janeiro - RJ - Brasil

uribe@ensp.fiocruz.br
} 
Mecanismos de aprendizagem (para a aquisição de capacidades gerais de resolução de problemas) precisam ser buscados em primeiro lugar ao nível psicológico. Se isto é coroado de êxito, com auxilio da psicologia do desenvolvimento cognitivo, tornam-se necessárias pressuposições empíricas adicionais, que possam explicar sociologicamente como processos individuais penetram no estoque de saber coletivo. A capacidade de aprendizado e as informações individualmente adquiridas precisam estar disponiveis, de forma latente em concepções do mundo, antes que possam ser utilizadas socialmente com êxito, i.e., transformados em processos de aprendizado da sociedade (Habermas J, Sobre a reconstrução do materialismo histórico, Suhrkampverlag, Frankfurt, p. 36).

\section{Introdução}

O tema em pauta nos obriga a estabelecer correlações entre gestão e subjetividade e o fazemos pelo lado da aprendizagem.

Essa determinação nos permite apresentar em grandes linhas entendimentos teóricos e proposições instrumentais típicos do paradigma gerencial da "organização que aprende", que corresponde a uma expressiva metáfora organizacional.

Introduzimos uma discussão sobre a liderança, que é uma categoria básica da gestão e dos processos de mudança organizacional que acentua o dilema entre o caráter subjetivo (ou individual) e o caráter social da condução desses processos.

Nosso objetivo não é o de negar a subjetividade inerente ao campo administrativo, mas de questionar o seu uso analítico como categoria ou instância separada dos processos de interação comunicativa que definem, desde o nosso ponto de vista, a essência da gestão administrativa.

\section{Aprendizagem, subjetividade e planejamento}

A subjetividade na gestão é um tema que está na ordem do dia em função da relativa crise da gestão procedimental e da emergência de uma nova visão que destaca a importância da cultura (na formulação dos objetivos organizacionais), da liderança comunicativa e da aprendizagem organizacional. A organização passa a ser concebida como uma sociedade que aprende a aprender.

A aprendizagem, para os teóricos da learning organization, deve ser vista como um processo contínuo com as seguintes etapas: (1) aprender a perceber ou a reinterpretar uma situação, (2) aprender como aplicar essa percepção para a formulação de uma política e especificação de uma ação, (3) aprender como implementar essas políticas e ações pretendidas, e (4) aprender como manter estes três últimos itens ativos, vivos, e abertos a constante revisão (site www.zumble.com.br, seção aprendizagem e desempenho).

Esta definição é importante porque se aproxima significativamente do escopo do planejamento, área de trabalho dentro da qual desenvolvemos nossa reflexão desde uma perspectiva situacional e comunicativa. A coincidência que se coloca entre nosso enfoque de base e o da organização que aprende tem a ver com a percepção da realidade como um processo mediatizado pelo nosso próprio recorte situacional, privilegiando aqui o ângulo de nossa cultura, de nossos valores e crenças. Essa percepção interessada da realidade, que extraímos de Matus (1993), confunde-se com a visão da realidade como processo que supõe o filtro de nossos próprios modelos mentais, termo caro aos teóricos da organização que aprende. Os modelos mentais são definidos por Senge e outros (1995) como pressupostos profundamente enraizados, generalizações ou imagens que temos, que influenciam o modo como percebemos o mundo e agimos sobre ele.

Maturana (1998) assume que a racionalidade é um plano constituído de premissas que aceitamos porque nos agradam (idéia que reforça o predomínio das emoções sobre o racional) e que o caminho que leva à percepção é o da objetividade entre parênteses, que significa que o ato de conhecer depende do observador e se estrutura como um convite ao outro a um tipo de diálogo sobre a validade das coerências operacionais do conhecer mesmo. Essa posição reforça a idéia matusiana de que existem várias formas de explicar uma mesma realidade, de acordo com a perspectiva específica do observador.

Mitroff (1999) é outro autor que assinala haver uma profunda relação entre a forma de analisar problemas e determinados tipos psicológicos derivados de uma interpretação do ser humano baseada em Jung. De acordo com esses tipos, uma mesma realidade poderá ser 
apreendida de maneira mais sistemática ou de uma maneira fragmentada e detalhista, mais voltada para tecnicismos ou para aspectos humanos e sociais. A particular subjetividade dos indivíduos contribuirá para a geração de explicações diferenciadas e para soluções várias que não comportariam o critério da solução "certa". Todas poderão ser encaradas como certas. Nessa medida, o ato de analisar problemas implica a necessidade de incorporar a maior parte dos envolvidos nos mesmos e de experimentar vários enunciados e explicações. Nessa linha da complexidade da análise de problemas, Mitroff formula, ainda, a idéia de que hoje em dia o paradoxo faz parte essencial da administração, pois a realidade reconhece várias situações "onde mais pode levar a menos", como por exemplo, a corrida armamentista.

Chama a atenção, neste autor, a mesma preocupação manifestada por Maturana acerca da influência das emoções e da espiritualidade na possibilidade de lidar com os fenômenos administrativos e da cognição em geral.

Não existindo, portanto, um conhecimento absoluto independente do observador, a primeira etapa da aprendizagem (interpretativa) se constitui como possibilidade de interação lingüística voltada para o questionamento dos modelos mentais que presidem a percepção dos vários observadores. Nesse particular, referimo-nos à aprendizagem como processo coletivo ou organizacional, que corresponde segundo Kim (1996) ao processo de transferência dos conteúdos da aprendizagem individual que redunda em um saber consensual, cristalizado como memória social tácita ou cultura. É esse processo de socialização do saber que fundamenta, habermasianamente, a validade relativa a contextos concretos do saber como racionalidade.

É extremamente interessante perceber que entre os teóricos da learning organization o planejamento é um processo de aprendizagem que permite o afloramento e o questionamento dos modelos mentais dos agentes tendo em vista a possibilidade de uma visão compartilhada. Arie P. de Geus (1997) sustenta assim que o verdadeiro propósito do planejamento eficaz não é fazer planos, mas mudar o microcosmo, os modelos mentais que os tomadores de decisões carregam em suas mentes.

Nessa perspectiva, a idéia burocrática de gabinetes de planejamento cede lugar a uma concepção dinâmica de laboratórios de aprendizagem, de oficinas de planejamento onde o que interessa é mais o processo que o resultado.

Para Kim (1996) a aprendizagem supõe um ciclo que se inicia com a captação de novos dados, referentes a reações do ambiente a uma ação implementada, que prossegue com a consideração de lembranças de experiências passadas no processo de atribuir significado ou de concluir algo sobre esse novo fragmento de informação (aprendizagem individual) e que se encerra com o armazenamento desses significados sob a forma de modelos mentais individuais. Este autor destaca que há duas formas de aprendizagem: o operacional, relativo a como implementar processos de trabalho e rotinas (às habilidades), e o conceptual, relativo ao porquê desses processos ou habilidades (ao conhecimento). Este último tipo seria o responsável pela introdução de novas realidades ao desafiar a natureza mesma dos processos existentes. A aprendizagem efetiva exigiria a presença de ambas as formas.

O mesmo autor assinala a existência de ciclos incompletos de aprendizagem:

- A aprendizagem situacional corresponderia a uma situação, em que mudanças no plano da percepção e da ação se dariam em contextos de muita especificidade, sem levar a modificações nos modelos mentais individuais (administração de crises).

- A aprendizagem fragmentada, que levaria à perda de conhecimento, corresponderia a um corte entre a aprendizagem individual $\mathrm{e}$ coletiva.

- A aprendizagem oportunista corresponderia a um tipo de orientação da ação que rompe seu vínculo com a memória organizacional.

A efetividade da aprendizagem dependeria de ir além da aprendizagem situacional e fragmentada e de se utilizar do aprendizado oportunista. Corrigir a aprendizagem situacional implicaria transferir as novas percepções específicas para mapas mais genéricos da realidade; situar esse novos dados em contextos de maior complexidade, caracterizados por um elenco mais abrangente e dinâmico de relações de causalidade (para o autor, os arquétipos sistêmicos de Senge podem ser de utilidade aqui). A superação do aprendizado fragmentado chama a atenção para a necessidade de laboratórios de aprendizagem onde se pratique o diálogo, a simulação coletiva, a argumentação e a indagação. A utilização do aprendizado oportunista corresponderia a um apelo no sentido do planejamento através de cená- 
rios, entendido como uma possibilidade de alargamento de horizontes capaz de levar a uma superação relativa do determinismo da cultura prévia.

Dada a nossa formação cultural, pensamos que a aplicação criativa, flexível e simplificada do raciocínio do planejamento estratégico-situacional supre em boa medida as exigências implícitas no pensamento sistêmico de Jay Forrester e Peter Senge. Referimo-nos, como anunciamos alhures, à idéia de uma explicação causal totalizadora (para além da departamentalização do saber) e rigorosa, no sentido de apontar causas subjacentes e essenciais. Ora, também vemos na operacionalidade das oficinas de trabalho de planejamento processos ou laboratórios de aprendizagem, onde a busca do consenso a partir das diferenças situacionais contribui para a superação do aprendizado fragmentado e para a geração de cultura ou de uma comunidade de idéias.

Pensamos, por outro lado, que o planejamento situacional matusiano deveria enfatizar uma importante opinião de Kim (1996), segundo a qual o modelo administrativo predominante de problema-solução pode levar a ofuscar a pertinência ou não do(s) problema(s) escolhido(s). Para este último, muito mais importante relativamente do que a própria problematização é a capacidade de articulação do problema, que corresponde à definição do mesmo como dependente de nossas premissas mais profundas ou modelos mentais. Assim, decompor um problema e descobrir um meio de o rearticular pode prover melhores condições que somente tentam redobrar esforços para solucioná-lo na forma em que se apresenta.

Uma das idéias que mais me impressiona em teóricos da learning organization diz respeito à relativa fragilidade da experiência para prover elementos para aprendizagem. Isso tem a ver, como apontamos alhures, com o conceito de complexidade dinâmica, que aprofundaremos mais adiante. Aqui podemos colocar de maneira simples que hoje em dia é extremamente difícil prever com algum grau de precisão as conseqüências de atos que praticamos hoje a partir de determinadas informações obtidas sobre problemas. Essas conseqüências podem ser remotas ou distantes no tempo e no espaço, devido à intermediação em um determinado ciclo informação-ação resultados de muitos outros ciclos e agentes. Dada essa difícil previsibilidade dos fenômenos a partir da experiência passada, surge a necessidade de aprender do futuro, entendendo a técnica de cenários como um diálogo - narrativa do futuro que no fundo seria um diálogo sobre os modelos mentais ou os filtros que aplicamos na percepção do futuro (técnica de cenários como "lembrança do futuro"). Esse diálogo pode ajudar a realinhar a visão. Não interessa tanto a probabilidade de uma dada narrativa. Ela poderá se constituir, como aprendemos de um aluno de um curso nosso, em uma espécie de "profecia auto-realizável", pela força da convicção representada pelo compartilhamento.

Gostaríamos de terminar esta parte com considerações sobre a aprendizagem como fenômeno individual que depende da socialização e de uma interação mais ampla com o meio, e, sobre a aprendizagem como mudança orientada para a ação.

Maturana (1998) assume a aprendizagem como um processo contínuo de mudanças de comportamento induzido pela necessidade de um acoplamento estrutural entre indivíduo e meio. A aprendizagem corresponde às mudanças ocorridas ao longo da vida em função de uma rede de interações com os outros e o meio, que se orienta para a adaptação em face de demandas recorrentes. Nesse processo histórico tanto se dá a (re)produção do indivíduo quanto do meio. A aprendizagem, como a cognição, está orientada para o fazer. Aprender é mudar para fazer. Aprender é fazer. Nesse contexto interpretativo, o nosso discurso sobre planejamento como aprendizagem remete à contínua necessidade de repercepção de situações para a delimitação de ações. Como Matus afirma, o fenômeno do planejamento é a mediação entre o conhecimento e a ação.

Piaget (in Freitag, 1985), ao se referir ao desenvolvimento ontogênico do indivíduo, sustenta a idéia de que essa evolução estaria caracterizada pelo fenômeno da "descentração”. A “descentração" constitui um processo de socialização que levaria a criança do monólogo (autista) ao diálogo, da ação e interação às operações hipotético-dedutivas, da prémoralidade à autonomia moral. Nesse percurso a criança faz um aprendizado em que passa a distinguir o mundo externo do mundo interno e subseqüentemente o mundo externo dos objetos do mundo social. A "descentração” reuniria dois movimentos concomitantes e complementares: o envolvimento crescente do indivíduo pelo grupo (socialização), 
traduzido em seu pensamento e sua linguagem socializada, e o distanciamento consciente do indivíduo com relação a seu grupo e às normas que regulamentam sua interação, traduzido numa crescente individualização e autonomização (conscientização).

A aprendizagem, embora basicamente individual, pressupõe, assim, uma relação permanente para fora, uma intersubjetividade e uma relação com o objeto em geral, em situações de práxis.

Dito de outro modo, as capacidades de cognição e de socialização que tipificam o mundo subjetivo ou da personalidade constituem estruturas que se alimentam principalmente da dinâmica das estruturas do mundo social, das normas e dos fatos sociais (Habermas, 1987).

Falar em subjetividade, então, é indissociável da intersubjetividade. O dilema que pesa sobre a aprendizagem é a possibilidade de superação do aprendizado fragmentado e situacional pela ingerência do diálogo ou da argumentação crítica.

Se a aprendizagem é primariamente individual, embora ocorra em contextos de acoplamento, a possibilidade de que ela venha a reverter em usos sistêmicos depende de sua transformação em concepções de mundo ou em sistemas de idéias dotados de legitimidade.

\section{As correntes da learning organization}

Têm sido identificadas três correntes (Boyett; 1999).

- Uma abordagem que considera que o principal obstáculo ao aprendizado individual e organizacional corresponderia à dificuldade de explicitar e questionar ("desafiar") livremente os modelos mentais dos participantes de uma organização. Este enfoque estaria representado pelo trabalho dos professores Christopher Argyris (especialista em educação e comportamento organizacional de Harvard) e Donald Schön do MIT.

- Uma abordagem que se concentra nos problemas de aprendizado que ocorrem quando os modelos mentais do tipo "se-então" estão incorretos por duas diferentes razões: (1) porque atribuem um relacionamento causal a alguns eventos e esse relacionamento não existe ou (2) porque não reconhecem esse relacionamento causal quando ele existe. Esta abordagem está mais associada ao trabalho de Pe- ter Senge, Jay W. Forrester e do Center for Organizational Learning do MIT.

- Uma abordagem mais cultural, representada pelo trabalho do professor do MIT Edgard Schein, que explora as relações entre as possibilidades de aprendizagem organizacional e as condições necessárias do ponto de vista da cultura organizacional.

O primeiro enfoque chama a atenção para a necessidade de desacelerar nossos processos mentais de modo a nos tornar conscientes de nossos modelos mentais, através da reflexão, e adquirir habilidades de indagação e de argumentação que colaborem para o questionamento de nossos modelos e dos modelos dos outros. Argyris sustenta que as pessoas tem a predisposição a tirar conclusões precipitadas acerca da conduta dos outros (a "subir a escada de inferência”), devido a uma leitura parcial dos dados da experiência e a uma interpretação enviesada desses dados em função de preconceitos ou crenças culturais arraigadas. Por outro lado, o autor assinala que o clima organizacional se caracteriza em geral pela presença de rotinas defensivas, que fazem parte de um modelo denominado de "incompetência qualificada"(Argyris, 1977), que apresenta alguns traços como: (a) tentar gerenciar o ambiente de trabalho visando ao maior controle possível dos fatores que o afetam; (b) aprovar e elogiar os outros. Dizer sempre o que você acredita que fará com que as outras pessoas se sintam bem em relação a si mesmas. Não ferir seus sentimentos. Dizer sempre o quanto se preocupa com elas e, se possível, concordar quando dizem que outras pessoas agiram inadequadamente. (c) Nunca confrontar as razões ou ações dos outros; (d) defender sua posição para vencer. Manter sua posição sempre. Sentir-se vulnerável a uma fraqueza. (e) Nunca dizer aos outros tudo o que você pensa ou sente; (f) manter seus princípios, valores e crenças.

Este autor sugere uma série de técnicas que visam trazer a tona e questionar o não dito presente em situações de interação malsucedida, e inserir em situações de diálogo um espírito de indagação, de auto-colocação autêntica e de crítica, que possibilite aumentar a capacidade de avaliação do comportamento defensivo e das conseqüências negativas não reconhecidas.

Senge é o autor que exerce a liderança mais forte dentro do campo da "organização que aprende”. No seu livro A quinta disciplina - 
Cadernos de Campo (1995, versão em espanhol, La quinta disciplina en la práctica), o autor condensa a contribuição de vários membros do movimento, ensejando aos leitores um acúmulo de técnicas pragmáticas ligadas à possibilidade do aprendizado. Este autor faz aportes específicos em duas áreas importantes de análise: a dinâmica de sistemas e a teoria da liderança.

Para Senge e Forrester, a dificuldade de reconhecimento dos relacionamentos de causalidade sistêmica se deve ao fato de que nossos modelos mentais traçam o quadro de um mundo unidirecional no qual um problema leva a uma ação que leva a uma solução. Nossos modelos mentais implicam uma estrutura simples como esta: informação sobre o problema $\rightarrow$ ação $\rightarrow$ resultado. No entanto, vivemos em um ambiente circular contínuo, onde cada ação baseia-se nas condições atuais, essas ações afetam as condições e as condições alteradas tornam-se a base de futuras ações. O processo não tem começo nem fim. As pessoas são interconectadas. Muitos desses loops são interligados. Através de longas cadeias de ações em cascatas cada pessoa reage continuamente ao eco de suas ações anteriores, bem como das ações dos outros. O mundo é uma longa mola de causalidade onde causa e efeito giram continuamente. Essa mola pode girar de forma ordenada ou esticar-se fortuitamente, com longos lapsos de tempo entre ação e resultado. Nos sistemas compostos de feedbacks em interação e longos intervalos de tempo, as causas de um sintoma observado podem ser provenientes de uma parte inteiramente diferente do sistema, e muito afastada no tempo. $\mathrm{Pa}$ ra confundir ainda mais as coisas, tais sistemas apresentam indícios que fomos condicionados a esperar. Mas, em geral, esses sintomas coincidentes ou causas aparentes surgem de uma causa distante. As pessoas são assim atraídas por ações que não são relevantes ao problema em questão.

Os autores propõem um treinamento no pensamento sistêmico, capaz de ajudar a melhorar as percepções desses relacionamentos de causalidade. Os principais elementos desse treinamento seriam:

- A modelagem dinâmica de sistemas, que consiste em criar sistemas ou modelos no computador, simular seu comportamento, explorar como os modelos reagem às mudanças na estrutura e nas políticas e comparar o comportamento do modelo com os sistemas reais que estão sendo apresentados. A modelagem de sistemas é uma atividade participativa na qual se aprende por tentativa e erro e pela prática. É o aprendizado pela surpresa dos erros cometidos.

- O uso dos chamados "arquétipos sistêmicos", termo cunhado por Senge para denotar certas regularidades ou padrões de comportamento sistêmicos que se verificam continuamente nas situações de negócios. O reconhecimento do tipo particular de arquétipo correspondente a uma dada situação problemática, assim como o exercício de uma estratégia de questionamento adequada a esse padrão de conduta poderiam melhorar o raciocínio sistêmico e prover eventuais alternativas de ação. - O uso de jogos de negócios, como os "micromundos" e "simumundos" (de Senge), que consistem em verdadeiros simuladores de vôo, onde os participantes tomam decisões e avaliam os resultados das mesmas em situações que não oferecem risco e que comprimem as dimensões de tempo e espaço. Esses jogos ajudariam a valorizar a interconexão dos eventos, a testar modelos mentais e a perceber o comportamento dinâmico de sistemas.

Como avançamos alhures (Rivera, 2000b), temos certas resistências à adoção de padrões interpretativos que não correspondem a nossos referenciais culturais. O desconhecimento dos elementos do pensamento sistêmico segundo a matriz de Forrester pode explicar essa reticência. Um certo incômodo nos gera a idéia de uns poucos arquétipos capazes de contemplar a diversidade de situações problemáticas vividas. Essa idéia nos sugere um certo reducionismo.

No entanto, aderimos às idéias de fundo contidas na análise de Senge, que consistiriam na nossa leitura na possibilidade de:

- Desenvolver explicações complexas da realidade, capazes de apontar para as causas essenciais dos fenômenos e para a relação dinâmica das causas em geral. O modelo de uma explicação situacional ao estilo matusiano, de natureza auto-referencial, policêntrica, totalizadora e rigorosa, pode suprir a necessidade de um enfoque de causalidade como o apregoado por Senge.

- Estabelecer práticas de simulação que exercitem o raciocínio do tipo "se-então". Neste caso, referimo-nos ao planejamento estratégico de cenários, que nos permite simular a construção de situações futuras como conseqüência da interconexão do comportamento de vá- 
rias variáveis-chave e da dinâmica dos atores sociais que controlam essa variáveis, e que nos ajuda a pensar o que fazer em situações alternativas de futuro. Esse raciocínio condicional seria um elemento do aprendizado organizacional de extrema importância, pois nos ajudaria a desenvolver a capacidade de mudar em função da circunstância real futura que pretendemos simular ex-ante com o nosso modelo. Nessa perspectiva, o confronto com várias possibilidades de futuro exerceria uma tensão contrária à rigidez de posições. Dado seu caráter redutor de variedade, preso ao essencial ou motriz, o planejamento de cenários seria também uma ferramenta auxiliar poderosa no desenvolvimento de um tipo de pensar voltado para a complexidade dinâmica, que definimos como uma narrativa que relativiza a extensividade do detalhe e que se prende ao movimento evolutivo de variáveis, tendências e relacionamentos realmente marcantes. Por fim, pensar o cenário futuro nos permitiria criar uma perspectiva oposta ao determinismo de nossa cultura, ao nos obrigar a pensar em novas possibilidades não claramente antevistas em função de nossa tradição.

- Estabelecer dinâmicas dialógicas que ajudem a discernir e a questionar os modelos de pensamento que subjazem às várias explicações possíveis de uma realidade. A radicalização da idéia de uma explicação situacional, que acentue o policentrismo e a necessidade de desvendar as premissas e os interesses valorativos que condicionam as leituras diferenciadas, insere-se nessa perspectiva.

Schein é o terceiro autor do movimento citado como formulador do enfoque cultural. A questão central que ele coloca é que tipo de cultura seria necessária à aprendizagem e como criá-la. A cultura necessária ao aprendizado apresentaria algumas características:

- Equilibra os interesses de todos os envolvidos: nenhum grupo domina o pensamento da gerência, pois é sabido que qualquer um desses grupos (clientes, funcionários, fornecedores etc.) pode retardar e destruir a organização.

- Concentra-se nas pessoas, não nos sistemas: acredita-se na capacidade das pessoas aprenderem, valorizarem o aprendizado e a mudança.

- Faz as pessoas acreditarem na possibilidade de mudarem seu ambiente. $\mathrm{O}$ autor se coloca a seguinte questão: se acreditarmos que o mundo ao nosso redor não pode ser modifica- do, de que adianta aprender a aprender? Relaxe e tire o máximo de seu destino.

- Encontra tempo para o aprendizado: um certo tempo de "folga" é desejável para ser usado para o aprendizado. Como diz o autor - ser enxuto e mau não é uma boa receita para o aprendizado organizacional.

- Adota uma abordagem holística dos problemas: estes apresentam dimensões múltiplas interconectadas e mecanismos de causalidade complexos.

- Estimula a comunicação aberta: há o compromisso com uma comunicação total e com a verdade. Desenvolveu-se um vocabulário comum que permite a comunicação.

- Acredita no trabalho em equipe: a competição individualista não é vista como a resposta para todos os problemas.

- Tem líderes acessíveis, que reconhecem sua vulnerabilidade e incerteza e se colocam como professores e agentes de mudanças e não como carismáticos responsáveis pela decisão.

Schein reconhece que a cultura que predomina nas organizações é o contrário e que, em geral, pelas induções dessa cultura e de um modelo cético da natureza humana não haveria espaço suficiente para o livre desenvolvimento do aprendizado coletivo. Nessa medida, o autor sugere a necessidade da criação de "portos psicologicamente seguros" para o aprendizado ou de sistemas paralelos (dentro ou fora da organização), onde as pessoas teriam oportunidades de treinamento e prática, apoio e estímulo para superar o medo e a vergonha de cometer erros, treinamento e recompensas pelos esforços na direção certa, e normas que recompensem a inovação e a experimentação. Schein desiste do núcleo da organização como possibilidade de um ambiente seguro que opere como berço do aprendizado para a mudança e defende que esse sistema paralelo deveria ser criado bem no topo da organização, tendo o executivo como o principal aluno e sendo representado por um grupo em torno dele.

Nesse particular, observa-se uma importante contradição entre Schein e Senge, na medida que este último considera um mito a ser combatido a idéia de que toda mudança importante vem de cima e sustenta uma visão ecológica da liderança, que subentende a necessidade de encarar toda a organização como a possibilidade de um ambiente seguro para o exercício da aprendizagem para a transformação. De qualquer maneira, subsiste a dúvida: 
como criar um ambiente seguro para a aprendizagem rompendo com o condicionamento de uma cultura impositiva sem apelar para induções externas?

Ocorre-nos aqui que buscar formas de distanciar-se da cultura, ao olhá-la de fora (através de uma mudança ambiental e do diálogo interdisciplinar); intensificar os processos comunicativos voltados para o processamento de aspectos disfuncionais da cultura para o encaminhamento pragmático de problemas reais; assim como, a afirmação das diferenças representadas pelos aspectos individuais ou subjetivos ofuscados pela noção de cultura podem representar pistas gerais para responder positivamente à questão anterior. Lembramos também da importância, já referida, do planejamento a partir de cenários como forma de distanciamento da tradição e da experiência acumulada.

\section{Liderança individual ou coletiva?}

Peter Senge tem se notabilizado por suas análises sobre a liderança. Em O novo trabalho do líder (Starkey, 1997), o autor procura caracterizar os requisitos da liderança da organização que aprende, as novas habilidades que ela deveria incorporar, referindo-se, ainda, a algumas ferramentas de desenvolvimento da liderança.

O líder deveria ser encarado, segundo o autor, como projetista, professor e regente.

No exercício do primeiro papel, a liderança se envolve como projetista dos ideais e propósitos da organização e, de sua tradução prática, das políticas e estratégias, construídas coletivamente. Se a responsabilidade primária da liderança é com esse planejamento, isso não quer dizer que esse ato seja solitário. O termo construção coletiva sugere conceber o processo de planejamento das políticas e estratégias como um processo de aprendizagem organizacional ampla. Citando Mintzberg, o autor assume que esse planejamento não pode ser visto como um esquema racional elaborado no plano abstrato e implementado em toda a extensão da organização, mas como um fenômeno emergente. Organizações de sucesso "fabricam sua estratégia”, uma vez que estão continuamente aprendendo com as constantes mudanças nas condições dos negócios, ponderando o desejável e o factível. O segredo não está em obter a estratégia certa, mas sim em promover o pensamento estratégico. A escolha da ação individual é apenas parte da necessidade do criador da política. O mais importante é a necessidade de conseguir enxergar a complexidade e de formular conceitos e visões de mundo para lidar com essa complexidade. A promoção de um ambiente de aprendizagem através da difusão do pensamento estratégico seria uma das funções essenciais da liderança.

O líder como professor corresponde à visão do mentor, do guia, do facilitador. Os objetivos fundamentais desse professor seriam trazer à tona e ajudar a reestruturar os modelos mentais e visões da realidade das pessoas e promover o pensamento sistêmico, no sentido daquele pensamento voltado para as causas estruturais ou profundas dos fenômenos.

O líder como regente das pessoas e da missão organizacional é uma instância que se compenetra dos ideais de alta responsabilidade que caracterizam uma organização que aprende e que se coloca a serviço dos interesses superiores da organização. O conceito de uma liderança que presta serviços (servant leadership) é o oposto da liderança egocêntrica.

Entre as habilidades que a liderança deveria desenvolver, Senge cita (Rivera, 2000a):

- A construção de visões compartilhadas, implicando alguns requisitos: a) o líder deve saber comunicar sua visão, pedir apoio e indagar sobre a posição dos outros, no sentido de conferir se ela merece o comprometimento dos outros e de se dispor a questionar seu ponto de vista, assumindo um tipo de construção interativa; b) as visões pessoais devem ser estimuladas e não anuladas; c) a construção da visão é um processo contínuo, que não se deixa apreender pela figura da "declaração da missão" em reuniões especiais, mas que corresponde a difusão de um tipo de pensar estratégico capaz de apoiar o questionamento quotidiano do que realmente queremos conseguir em cada circunstância prática; d) a liderança deve poder combinar visões extrínsecas (do tipo "derrotar um oponente") com visões intrínsecas (criar um novo produto, um novo padrão de satisfação de necessidades); e) a liderança deve saber distinguir visões positivas (alicerçadas em aspirações) e negativas (baseadas no medo), fortalecendo as primeiras.

- Trazer à tona e testar modelos mentais, implicando alguns requisitos: a) a possibilidade de perceber saltos de abstração, questionando generalizações; b) equilibrar indagação e ar- 
gumentação, assumindo que situações complexas exigem um aprendizado cooperativo; c) distinguir a teoria esposada (o que a pessoa diz que faz) da teoria em uso, assumindo que a distância entre o declarado e o real em uso implícito é crítica para o aprendizado; d) reconhecer e dissipar rotinas defensivas

- Desenvolver o pensamento sistêmico, que corresponde a: a) enxergar inter-relações, não coisas, processos, não fotos instantâneas; b) ir além das acusações, assumindo que a fonte das falhas não são as pessoas, mas os sistemas; c) concentrar-se na complexidade dinâmica (saber relacionar causas e efeitos distantes no tempo e espaço e distinguir conseqüências remotas) e não na complexidade de detalhes; $d$ ) concentrar-se, em termos da ação, em áreas de alta alavancagem; e) evitar soluções sintomáticas.

- Definir dilemas estratégicos: refere-se à capacidade de evocar os dilemas ou de distinguir os valores distintos e às vezes aparentemente conflitantes atrás das decisões (por exemplo, custo e qualidade), procurando sintetizá-los. Como acréscimo apontaríamos, aqui, a capacidade de lidar com paradoxos, na linha do posto por Mitroff.

- Criar uma rede de proteção para a reflexão individual e coletiva, capaz de sustentar a possibilidade da inovação e da mudança. Aqui, a capacidade de garantir um tempo livre para a reflexão dos sujeitos organizacionais é fundamental.

No livro A dança das mudanças (1999), Senge desenvolve a versão mais atualizada de sua concepção de liderança. A partir da metáfora do jardim, o autor se contrapõe à imagem da liderança-herói. A liderança "jardineiro" não é aquele tipo que prostrado sobre as plantas implora: "Cresçam plantas, cresçam com afinco". Essa liderança, ao contrário, reconhece que o crescimento das mesmas depende de seu potencial e se decide a acompanhar seu ciclo natural, preocupando-se com as condições que reforçam e que limitam seu crescimento (água, solo, nutrientes, sol, outras árvores...). Atrás dessa imagem está a idéia de que as organizações devem ser vistas como sistemas biológicos e não como máquinas. No caso de uma concepção maquinal da organização, quando surge um problema, este é assimilado à condição de uma peça defeituosa que deve ser trocada. Na concepção biológica organizacional, lidamos com gente, com pessoas, que assim como as plantas, não podem ser tratadas co- mo peças de uma engrenagem maquinal. No caso do jardim, uma planta não morre para ser substituída por outra, simplesmente. O que acontece é que uma nova vai crescendo e acaba por tomar o lugar da velha. O mesmo ocorre com o comportamento. Se um comportamento novo é mais eficaz do que o antigo, então o novo acaba conquistando espaço. Dessa maneira, o líder-jardineiro seria aquele que tenta atuar sobre as condições limitadoras e promotoras do desenvolvimento potencial das pessoas organizacionais, especialmente sobre as condições básicas para uma aprendizagem coletiva solidária. Seriam essas as condições de aprendizado, fatores propulsores ou realizadores do potencial de crescimento das pessoas, potencial esse que poderia ser tolhido em contextos impositivos e objetivantes.

A liderança para Senge não seria um fator individual. Ou apenas individual. $\mathrm{Na}$ sua visão ecológica de liderança, esta corresponde a uma capacidade coletiva para moldar as mudanças. Na organização haveria vários líderes, em vários níveis, não necessariamente executivos. Destacam-se dentre eles os "que portam a semente", isto é, aqueles que têm a capacidade de estabelecer redes mais ou menos informais de comunicação, de impulsionar a todos os níveis, em relações de transversalidade, a possibilidade da transferência de habilidades e de conhecimentos. Esses líderes retirariam seu potencial da capacidade de estabelecer interconexões entre inovadores.

Para o autor, os grandes problemas que a mudança enfrenta são de tipo gerencial. Referem-se à incapacidade de gerar uma dinâmica de negociação de uma visão compartilha$\mathrm{da}$, à dificuldade de trazer à tona temas "indiscutíveis" mediante o desenvolvimento de habilidades de reflexão e indagação, à tendência de evitar o enfrentamento das causas mais complexas dos problemas em prol de um tratamento sintomático, a um tipo de conduta defensiva que escamoteia medidas que podem afetar interesses, etc.

Essas restrições, típicas da despreocupação dos dirigentes com a aprendizagem coletiva, podem ser compensadas através de estratégias de aprendizagem. Mas isso não é suficiente. A mudança exigiria uma maior concentração sobre os aspectos limitadores do crescimento, entendendo mudança não como troca ou substituição, ou produção de algo absolutamente novo, mas como crescimento (como evolução do novo a partir do antigo). A referência de 
Senge a Maturana: "a história é a transformação para a conservação”, ou dito de outra forma: "cada movimento está sendo inibido à medida que ocorre", corresponde ao reconhecimento de tendências naturais de compensação ou de limitação do crescimento, que deveriam ser o alvo privilegiado de uma reflexão estratégica sobre como agir para enfraquecer ou atenuar essas tendências e para adiar os momentos de inflexão compensadora. Toda esta reflexão aponta para a necessidade de pensar não em termos de impor mudanças, mas de cultivar mudanças.

Essa perspectiva não pretende afirmar que a liderança não seja individual. Trata, isso sim, das relações entre capacidades individuais e sociais. Tenciona reforçar a idéia de que líder é quem fomenta os processos de aprendizagem que podem gerar uma liderança disseminada.

Motta (1991) formula que a essência da liderança consiste de capacidades de domínio do contexto (capacidades de análise estratégica do ambiente e dos problemas organizacionais, de intuição do futuro e de formulação da visão), capacidades de manejo intersubjetivo (comunicação e negociação) e individuais (como o bom conhecimento de si, a capacidade de socialização e a autenticidade). Reforçando a dimensão subjetiva, o autor se detém na importância do ilógico e da intuição na gestão administrativa, que explicam o caráter às vezes pouco coerente e racional da mesma. $\mathrm{O}$ mesmo acrescenta que a intuição mistura elementos de racionalidade formal e informal e que esta se apóia fortemente na experiência acumulada pela liderança. Esse destaque dado à dimensão subjetiva não formal ou racional da liderança opera aqui como um argumento importante para não omitir a natureza individual da mesma.

Em Bennis (Rivera, 2000), encontramos, por fim, idéias importantes sobre a liderança como um fenômeno voltado prioritariamente para a mobilização das pessoas (e não necessariamente para a indução da motivação), para a reflexão futurista da grande visão em detrimento do detalhe operacional e para o desenvolvimento da inovação. Diferentemente da lógica do controle inerente à gestão tecno-burocrática clássica, o fenômeno da liderança atuaria como o exercício do poder para o desenvolvimento de dinâmicas de equipe e de interação disciplinar que favoreceriam a inovação e a mudança. A promoção da liderança de- penderia muito de um tipo de aprendizado caracterizado pelo trânsito cultural entre disciplinas diferenciadas e informações aparentemente distantes. Essa linha de pensamento reforça, portanto, a idéia da liderança como processo de aprendizagem e como instância de mobilização das capacidades individuais e intersubjetivas da organização.

\section{Conclusão}

O nexo que estabelecemos entre subjetividade e gestão corresponde ao entendimento da organização como sociedade que aprende e do planejamento como comunicação voltada para a discussão crítica dos vários modelos mentais (no limite, individuais) envolvidos na análise de problemas.

A aprendizagem é entendida como processo individual de aquisição de conhecimentos e habilidades dependentes da socialização e de processos de acoplamento com o meio, no sentido trabalhado por Maturana e por Piaget em relação ao processo de cognição em geral.

A aprendizagem como processo social corresponderia à superação do aprendizado fragmentado, que ocorre quando o aprendizado individual não implica a transferência de conteúdos para os grupos e organizações (ou no compartilhamento).

A subjetividade é portanto indissociável da intersubjetividade e se expressa na gestão por referência à última. Isso não implica a sua dissolução ou anulação no ou pelo patrimônio social ou cultural. A diferença não pode ser negada, deve ser afirmada quando necessário.

A questão da liderança oferece um campo interessante para a reflexão sobre como características subjetivas e sociais ligadas à gestão organizacional se remetem mutuamente. Liderança é tanto uma capacidade individual como social, entendida a mesma tanto como resultado quanto como possibilidade da aprendizagem organizacional.

As capacidades de reflexão e de diálogo, de argumentação e de indagação, a capacidade de trazer à tona o não dito que condiciona a fala dos sujeitos organizacionais e de questionar os indiscutíveis de uma organização, o uso do planejamento de cenários como "lembrança do futuro" (análise dos filtros mentais que condicionam nosso olhar para o futuro) e aprendizado da capacidade de mudar, a análise de 
problemas como possibilidade de questionamento de nossas crenças são, entre outras, capacidades de aprendizagem que podem redundar em visões compartilhadas, superando o aprendizado fragmentado, e gerando um saber comum que alimenta a cultura de uma organização.

A afirmação da individualidade e um distanciamento em relação à cultura podem significar, porém, a possibilidade da diferença inovadora.

\section{Referências bibliográficas}

Argyris CD 1977. Loop learning in organizations. Harvard Business Review, set./out., pp. 118-119.

Boyett J 1999. O guia dos gurus. Os melhores conceitos e práticas de negócios. Ed. Campus, Rio de Janeiro, 374 pp.

Freitag B 1985. Piaget. Encontros e desencontros. Ed. Tempo Brasileiro, Rio de Janeiro, 144 pp.

Geus AP 1997. Planejamento como aprendizado, pp. 115-125. In Starkey K. Como as organizações aprendem. Relatos do sucesso das grandes empresas. Zumble/Futura, São Paulo.

Habermas J 1987. Teoria de la acción comunicativa. Taurus Ed., Madri, 850 pp.

Kim D 1996. Administrando os ciclos de aprendizado organizacional, pp. 65-77. In Wardman KT. Criando organizações que aprendem. Zumble/Futura, São Paulo.

Kim D 1996. Loops de criação de paradigmas: como as percepções moldam a realidade, pp. 81-89. In Wardman, op. cit.

Maturana H 1998. Emoções e linguagem na educação e na política. Ed.UFMG, Belo Horizonte, 120 pp.

Matus C 1993. Política, planejamento e governo. Ed. Ipea, Brasília, 520 pp.
Mitroff I 1999. Tempos difíceis. Soluções inovadoras. A arte de fazer as perguntas certas e resolver os problemas certos. Ed. Campus, Rio de Janeiro, 181 pp.

Motta P R 1991. Gestão contemporânea. A ciência e a arte de ser dirigente Ed. Record, Rio de Janeiro, 256 pp.

Rivera FJU 2000a. Cultura e liderança comunicativa - a gestão pela escuta 1. ENSP, Rio de Janeiro, $25 \mathrm{pp}$. (mimeo)

Rivera FJU 2000b. Reflexões sobre a organização que aprende. A gestão pela escuta 3 - Algumas ferramen tas lúdico-pragmáticas. ENSP, Rio de Janeiro, 28pp. (mimeo)

Senge $\mathrm{P}$ et al. 1995. La quinta disciplina en la práctica. Estrategias y herramientas para construir la organización abierta al aprendizaje. Ed. Granica, Barcelona, 590 pp.

Senge P et al. 2000. A dança das mudanças. Os desafios de manter o crescimento e o sucesso em organizações que aprendem. Ed. Campus/Zumble, Rio de Janeiro, $676 \mathrm{pp}$.

Senge P 1997. O novo trabalho do líder, pp. 342-375. In Starkey K. (org.). op. cit 